\title{
Gary Mayerson: How to Compromise with Your School District Without Compromising Your Child: A Field Guide for Getting Effective Services for Children with Special Needs
}

\author{
Drl Books, New York, NY, 140 pages, \$24.95
}

\author{
David O. Black
}

Published online: 30 September 2009

(c) GovernmentEmployee: National Institutes of Health 2009

Mayerson's book provides a solid foundation for parents and providers who are working with school systems to develop effective intervention programs for children with special needs. Written by a lawyer with a practice dedicated to representing children with autism and developmental disabilities, the primary objective of the text is to prepare parents for the potentially adversarial process of developing an appropriate individualized education plan (IEP) for a child with special educational needs. Introducing the topic, the author begins by helping the reader understand the perspective and pressures of school systems in trying to manage an ever growing population of children with special education needs in the midst of limited staff and constant budget pressures. It provides perspective from parents, educational specialists, and individuals within various school district special education departments to provide insight into why developing an IEP is often so challenging. Through case examples, the text also helps parents understand their legal role in the IEP process and the value of their input in ensuring the IEP is appropriately tailored to their child. Mayerson helps parents prepare for potential pitfalls at IEP meetings by helping them prepare themselves to best advocate for their child and to anticipate how the school district may respond to their questions.

The text touches on a wide variety of relevant topics, such as the importance of thorough documentation of your child's progress, the legal distinction of "maximizing" a child's potential and an "appropriate public education,"

\footnotetext{
D. O. Black $(\varangle)$
}

National Institute of Mental Health,

Pediatrics and Developmental Neuroscience Branch,

National Institutes of Health, 10 Center Drive MSC 1255,

Building 10, Room 4N208, Bethesda, MD 20892-1255, USA

e-mail: blackdavid@mail.nih.gov and communication with the school district. It provides insight into how partial or inaccurate documentation may impact the services a child receives and, therefore, the importance of inspecting and maintaining an accurate educational record. It also explains little discussed concepts, such as parents engaging in "inequitable" conduct, through which an IEP hearing officer could remove previously approved services. A substantial chapter is dedicated to the IEP meeting itself. This chapter discusses what may seem to be mundane, but in fact are quite important topics, including dressing appropriately, managing the IEP meeting agenda, determining whether key players will be in attendance, and getting essential questions answered. A discussion of various strategies to challenging the school district's IEP recommendations is also offered. Mayerson presents general strategies for IEP meetings, such as whether to bring your lawyer to the meeting and when to request an outside evaluation. Other chapters are dedicated to enlightening the reader about educational concepts such as the Least Restrictive Environment, extended school day/ school year, and mediation.

While this guide provides a good introduction to the IEP process, along with some perspective on the tenor and potential acrimony that is present in some IEP meetings, it focuses less on what makes a good IEP. There is also very little discussion of how to develop appropriate and welldefined educational goals, how to best monitor a child's academic progress, or prioritization of educational goals when confronted with a child who has complex educational needs. Most of Mayerson's legal work involves advocating for children with autism spectrum disorders, and the illustrations given in the text nicely reflect this experience. I would recommend this book to anyone preparing for their first IEP meeting, particularly if they have any reason to expect the process to be contentious. 